\title{
Balance impairment and lower limbs strength in patients with COPD who fell in the previous year
}

\author{
Elias F. Porto ${ }^{1}$, Antonio A.M. Castro², Daniela M. Fausto² ${ }^{2}$, Claudia Kümpel ${ }^{1,3}$, Ana Denise Brandão ${ }^{1}$, \\ Paula Bernado de Lima ${ }^{1}$, Jordania C. Fagundes ${ }^{3,4}$, Brenda Zozimo ${ }^{3,5}$ \\ ${ }^{1}$ Adventist University of São Paulo (Unasp); ${ }^{2}$ Federal University of Pampa (Unipampa), Rio Grande do Sul; \\ ${ }^{3}$ Pulmonary Rehabilitation Centre, Adventist University of São Paulo (Unasp); ${ }^{4}$ Physiotherapy Curse, Adventist \\ University of São Paulo (Unasp); ${ }^{5}$ Physiotherapy and Health Promotion program, Adventist University of São Paulo \\ (Unasp), Brazil
}

\begin{abstract}
Fall-related causes in patients with COPD might be associated to functional balance impairments and greater disease severity. We aimed to evaluate the reasons for falls in patients with COPD who
\end{abstract}

Correspondence: Elias Ferreira Porto, Respiratory Diseases (Physical
Therapy - Adventist University of São Paulo), Estrada de Itapecerica
5859, 5859001 São Paulo, SP, Brazil.
E-mail: eliasfporto@gmail.com

Key words: COPD; falls; postural balance.

Contributions: EF, substantial contributions to the conception, design of the work, data interpretation, work draft, substantially revised and approved the submitted version; AAMC, data interpretation, work draft and substantially revised; DMF, CK, work draft and substantially revised; ADB, PBL, BZ, JF, data acquisition and analysis. All the authors read and approved the final version of the manuscript and agreed to be accountable for all aspects of the work.

Ethics approval and consent to participate: The study was approved by the Ethics Review Board of Adventist University of São Paulo (number 0369/10). All subjects signed an informed consent.

Conflict of interest: The authors declare that they have no competing interests, and all authors confirm accuracy.

Received for publication: 28 November 2019.

Accepted for publication: 16 December 2021.

Publisher's note: All claims expressed in this article are solely those of the authors and do not necessarily represent those of their affiliated organizations, or those of the publisher, the editors and the reviewers. Any product that may be evaluated in this article or claim that may be made by its manufacturer is not guaranteed or endorsed by the publisher.

COpyright: the Author(s), 2022

Licensee PAGEPress, Italy

Monaldi Archives for Chest Disease 2022; 92:1204

doi: 10.4081/monaldi.2022.1204

This article is distributed under the terms of the Creative Commons Attribution-NonCommercial International License (CC BY-NC 4.0) which permits any noncommercial use, distribution, and reproduction in any medium, provided the original author(s) and source are credited. had presented any fall during the previous year. This is a crosssectional study. All COPD's GOLD classifications (mild, moderate, severe, and very severe) patients were recruited. In order to participate, patients ought to be clinically stable and without any exacerbation within 30 days prior to study entry. History of falls was self-reported by patients through an interview. Pre and post bronchodilator (salbutamol $400 \mu \mathrm{g}$ ) spirometry was performed. All patients accomplished postural balance tests such as the Berg Balance Scale, Falls Efficacy Scale-International, Time up and Go, Functional Reach test, Tinetti test and Chalder Scale; furthermore, lower limbs muscle strength (muscle dynamometry) and the COPD Assessment Test (CAT) were assessed. Ninety-six patients with COPD were evaluated and divided into two groups stratified according to any positive history of falls in the previous year. Patients with COPD who had any fall in the previous year presented older age $(p=0.01)$, higher BMI $(p=0.04)$ and worse pulmonary function than those who did not fall. The risk of falls was increased in patients with lower muscle strength in the lower limbs (OR 2.9, CI 95\%;1.6 to 3.9), age greater than 65 years (OR 2.7 , CI $95 \% ; 1.3$ to 3.4 ), BMI greater than $28.8 \mathrm{~kg} / \mathrm{m}^{2}$ (OR $3.2, \mathrm{CI}$ $95 \% ; 1.1$ to 5.6 ), very severe airway obstruction (OR 3.9, CI $95 \% ; 2.2$ to 3.9 ) and fatigue (OR 3.2, CI 95\%;1.5 to 5.3). Impaired body balance, reduced lower limb strength, disease severity, presence of fatigue and elevated BMI are important factors for falls in patients with COPD.

\section{Introduction}

Chronic obstructive pulmonary disease (COPD) is a respiratory disease that results in airflow limitation and respiratory distress [1]. The disease manifestations, however, are not exclusively limited to respiratory function and patients with COPD face many non-respiratory impairments that affect both function and mobility. Deficits in function and mobility have been associated with an increased fall risk in older adults [2,3]. Primarily, risk of falls is mainly associated to muscle depletion in these patients. A study that assessed balance in patients with COPD observed that hypoxemia, dyspnea and fatigue are disease related factors related with balance impairment and falls in these patients. Associated mechanisms such as muscle dysfunction and hypotrophy may also be important related factor4. Some evidence explains these changes through time; as disease develops, COPD patients may increase induced muscle dysfunction/depletion and, therefore, weakness, exponentially, increasing risk of falls [4]. For this reason, literature suggests that muscle 
assessment and training carried out to improve balance in elderly patients with COPD should be a component of pulmonary rehabilitation programs in clinical practice [5].

On the other hand, a lack of evidence is seen on other possible explanations for fall risk in this population. For instance, no evidence suggests that visual deficits can increase risk of falling in COPD. In addition, syncope and postural hypotension as a fall triggering mechanism is unclear. Exacerbations and dyspnea are not directly associated with fall risk but, secondarily, can contribute to the progressive physical deterioration that may increase the risk of falls in these patients. While these results suggest that patients with COPD might have an increased susceptibility to fall compared to their healthy peers [6], no information is yet established on what extent systemic manifestations can be the causes of such falls [7].

Despite of that, it is known that impaired functional balance may play an important role on fall development in COPD patients [8]. Recently, it has been seen that body balance impairment and a greater incidence of falls is more frequent in patients with COPD than in healthy subjects while performing dynamic activities [9]. Therefore, we aimed to evaluate the reasons for falls in patients with COPD who had presented any fall during the previous year.

\section{Materials and Methods}

This is a cross-sectional study on patients with COPD who were conveniently recruited from the rehabilitation center of the University Polyclinic at Adventist University of São Paulo, Brazil. Our university Ethics Review Board (number 0369/10) has approved this study and all subjects signed an informed consent.

Inclusion criteria were: mild, moderate, severe, and very severe airway obstruction (according to the GOLD 2017 criteria) [1]; stable clinical conditions without any exacerbation within 30 days prior to the study entry (i.e., not having increased dyspnea, cough, sputum or even increased global fatigue). Exclusion criteria were: associated comorbidities such as cardiac, orthopedic and neurological diseases that would not allow normal lower limbs function; inability to perform spirometry; lack of procedures understanding; current smoker or former smoker prior to one year.

All participants performed the following procedures: spirometry in forced vital capacity (FVC) mode - pre and post $400 \mathrm{mcg}$ of salbutamol ${ }^{\circledR}$ - to assess clinical conditions [1]. In order to assess body balance the Berg scale [10], Functional reach tests [11], Falls Efficacy Scale - International [11], Time up and Go [12], Tinetti test $[13,14]$, Chalder Scale [15] were used; also, quality of life was also assessed using the CAT questionnaire [16]. Clinical characteristics of patients were assessed using our own University facility questionnaire; it comprises height, weight, gender, medical and physical records and current medicine intake.

Patients underwent two visits at the laboratory. On the first day they underwent spirometry with and without bronchodilators and completed the quality-of-life questionnaire [16]; also, anthropometric data and previous falls were recorded. History of falls was selfreported by patients through an interview. On the second day, the clinical stability questionnaire was answered and body balance tests were performed. Spirometry was carried out with three acceptable spirometric evaluations (KoKo; Occupational Health Dynamics; Birmingham, AL, USA) and were done following the American Thoracic Society/European Respiratory Society recommendations. FVC, slow vital capacity (SVC), and forced expiratory volume in the first second $\left(\mathrm{FEV}_{1}\right)$ in liters were measured. Spirometry was repeated $15 \mathrm{~min}$ after a bronchodilator administration (albuterol 400 mcg); predicted values for $\mathrm{FVC}$ and $\mathrm{FEV}_{1}$ were calculated according to the third National Health and Nutrition Examination Survey [17]. Severity of disease was classified according to Global Initiative for Chronic Obstructive Lung Disease stages [1].

Body balance was assessed by Berg Balance Scale [10]. It evaluates functional balance in 14 daily life activities with an overall of 56 points. Scores between 45 to 56 points are associated with a decreased risk of falling and scores under 36 points are related to a fall risk that is up to $100 \%$. The cutoff score for impaired balance is 45 points. The fear of falling was assessed while performing daily and leisure activities according to the Falls Efficacy ScaleInternational questionnaire [11]. This questionnaire consists of 16 questions and evaluates the predisposition to falls in elderly population during every day and leisure activities. Functional mobility was assessed using the Time up and go test, which can qualify mobility as normal, fragile or incapacity levels; the longer the time to perform the test, the worse functional mobility is [12]. Body flexibility was assessed by the Functional Reach test; the lower the body flexibility the worse the balance is [13]. Also, as a balance measure, the Tinetti scale has 14 balance related items (overall score up to 24 points) and 10 gait related items (overall score up to 16 points). It can be scored up to 40 points and higher scores correspond to better a performance $[13,14]$. Finally, global fatigue was evaluated using the chalder scale; the greater the global fatigue is, the greater the risk of falling [15]. Muscle strength was assessed using a dynamometry device, the percentage of age predicted was used as a reference source [8]. CAT questionnaire was used to assess quality of life. CAT ranges from 0 to 40 points. Scores between 0 to 10 has no impact on quality of life, scores between 11 to 20 suggests low impact, scores between 21 to 30 suggests medium impact and scores between 31 to 40 suggests high impact of COPD's quality of life [16].

\section{Statistical analysis}

Data are presented as mean and standard deviation. The Student's $t$-test was used to compare the differences between the anthropometric variables, pulmonary function and body balance data between patients with COPD with and without falls in the previous year. Analysis of variance of one entry (one-way repeated measures) with Tukey post hoc test was used to assess the number of falls (none, one, two or three falls) patients reported in the previous year. Risk of falls was done by univariate odds ratio test. Statistical significance was determined by a $p<0.05$. We used the GraphPad Prism ${ }^{\circledR}$ software (9.1.0 version) to plot all statistics. Considering an $\alpha=0.05$, and a statistical power of $80 \%(\beta=0.20)$ according to the dichotomic outcome variable (increased or reduced risk of falls) our sample size would be of, at least, 84 patients in order to achieve significant statistical power.

\section{Results}

We evaluated 96 patients with COPD who were divided into two groups stratified by positive history of falls in the previous year. Fifty-nine (61.45\%) patients reported at least one fall prior to a twelve-month period. The characteristics of the COPD patient who reported falls in the last year prior to the study was evaluated. These were older $(p=0.010)$, had a higher BMI $(p=0.04)$ less forced vital capacity $(\mathrm{p}=0.021)$ and less forced expiratory volume over 
time $(\mathrm{p}=0.031)$. No change after the use of bronchodilator was seen in those variables (Table 1). After several tests accomplished, we observed a worse body balance in patients who fell compared to patients who did not fall. However, statistical significance was only seen on the BERG and Tinetti scales (Figure 1). Our study also showed that patients who reported three or more falls as compared to none scored worse in BERG [41.4(3.5) vs 52.3(2.4), $\mathrm{p}=0.001]$, Tinetti [43.5(4.1) vs 55.3(4.6), $\mathrm{p}=0.001]$ and fatigue [1.2(1.1) vs 2.9(1.4), $\mathrm{p}=0.03$ ] questionnaires. Additionally, patients who reported three or more falls as compared to none showed decreased lower limbs strength [13.2(3.3) vs. 22.1(1.8), $\mathrm{p}=0.049$ ]. On the other hand, patients who reported three or more falls as compared to none showed a longer TUG test performance [13.1(1.1) vs 11.2(1.3), $\mathrm{p}=0.049]$. No difference was seen between fallers and non-fallers with CAT scores. Lower and upper limbs muscle strength was also evaluated; we found that patients who reported falls in the last year showed a significant reduction in the lower limbs strength $(\mathrm{p}=0.047)$ - mean value was $21.9(7.7)$ and
25.8(9.6), CI 95\%; 20.6 to 23.4 and 22.7 to 28.8 (Figure 2). The risk of falls was assessed using the odds ratio. We found increased risk for patients with lower muscle strength in the lower limbs (OR 2.9 , CI $95 \%$; 1.6 to 3.9 ), age greater than 65 years (OR 2.7, CI $95 \% ; 1.3$ to 3.4 ), BMI greater than $28.8 \mathrm{~kg} / \mathrm{m}^{2}$ (OR 3.2, CI $95 \%$; 1.1 to 5.6 ), very severe airway obstruction (OR 3.9, CI 95\%; 2.2 to 3.9 ) and fatigue (OR 3.2, CI 95\%; 1.5 to 5.3) (Figure 3).

\section{Discussion}

The main objective of this study was to evaluate the characteristics of patients with COPD who had falls. Our main findings were: first, patients with COPD who had any fall in the previous year were older, presented higher BMI and worse pulmonary function than those who did not fall. Second, the risk of falls was increased for patients with reduced lower limbs strength, aged over

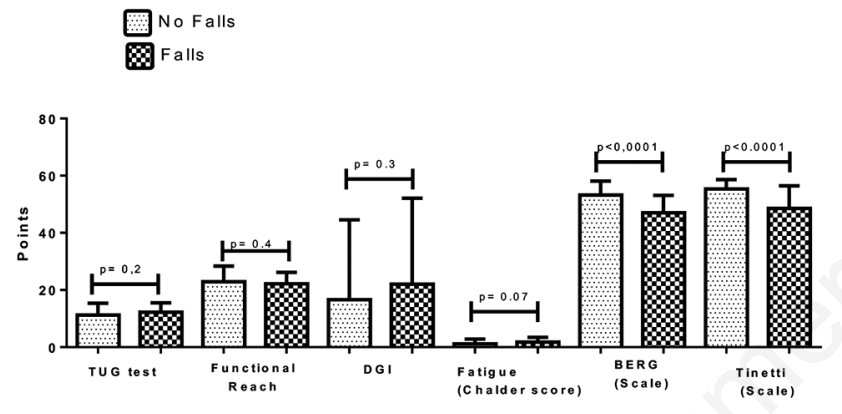

Figure 1. Body balance assessment in patients with COPD with and without a positive history of falls. Tug test, timed up and go test; DGI, dynamic gait index.

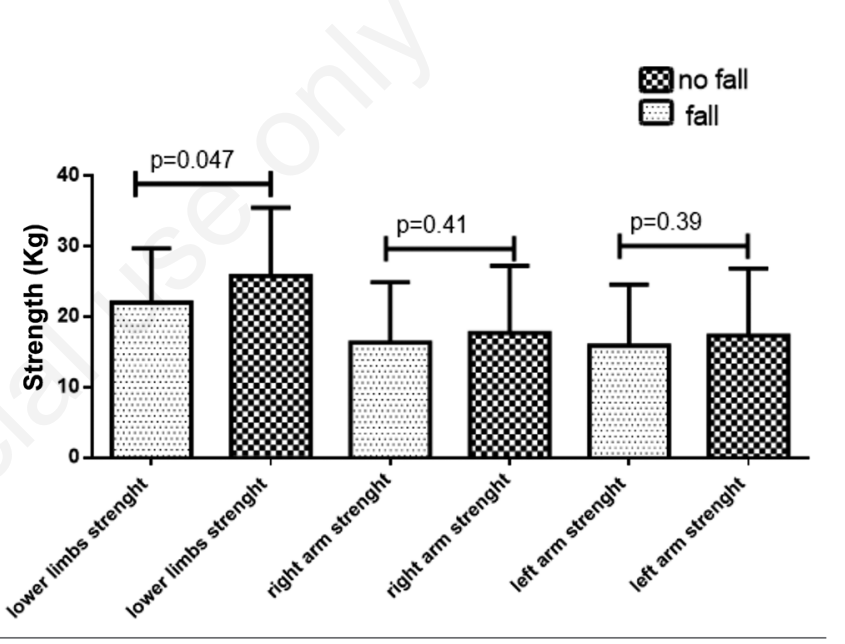

Figure 2. Muscle strength in patients with COPD with and without a positive history of falls.

Table 1. Anthropometrics, lung function and quality of life characteristics in the studied sample.

\begin{tabular}{|c|c|c|c|}
\hline Variables & Falls $(n=59)$ & No falls $(n=37)$ & p \\
\hline Age (years) & $69.9(7.7)$ & $65.5(9)$ & 0.01 \\
\hline Female (\%) & 52.6 & 54.2 & 0.09 \\
\hline Male (\%) & 47.4 & 45.8 & 0.06 \\
\hline BMI $\left(\mathrm{kg} / \mathrm{m}^{2}\right)$ & $28.5(3.6)$ & $25.6(3.1)$ & 0.04 \\
\hline FVC (L) & $2.4(0.2)$ & $2.66(0.86)$ & 0.021 \\
\hline FVC (\%) & $77(15.6)$ & $76(16.7)$ & 0.32 \\
\hline $\mathrm{FEV}_{1}(\mathrm{~L})$ & $1.26(0.19)$ & $1.65(0.94)$ & 0.031 \\
\hline $\mathrm{FEV}_{1}(\%)$ & $52.6(0.17)$ & $59.7(28.1)$ & 0.09 \\
\hline $\mathrm{FEV}_{1} / \mathrm{FVC}$ & $0.60(0.21)$ & $0.6(0.12)$ & 0.85 \\
\hline FVC (L) post bronchodilator & $2.52(0.07)$ & $2.71(0.84)$ & 0.025 \\
\hline FVC (\%) post bronchodilator & $80.9(14.5)$ & $79.7(15.1)$ & 0.87 \\
\hline $\mathrm{FEV}_{1}(\mathrm{~L})$ post bronchodilator & $1.21(0.29)$ & $1.66(0.61)$ & 0.0021 \\
\hline $\mathrm{FEV}_{1}(\%)$ post bronchodilator & $52.3(21.6)$ & $59.9(15.4)$ & 0.52 \\
\hline $\mathrm{FEV}_{1} / \mathrm{FVC}$ post bronchodilator & $0.59(0.11)$ & $0.61(0.21)$ & 0.85 \\
\hline Pack-year & $51.6(19.7)$ & $44.4(31.5)$ & 0.55 \\
\hline CAT (points) & $18.9(7.4)$ & $16.7(9.1)$ & 0.47 \\
\hline
\end{tabular}

BMI, body mass index; FVC, forced vital capacity; FEVI, first second expiratory volume; FEVI/FVC, first second expiratory volume/ forced vital capacity; CAT, COPD assessment test. 
65 years, BMI greater than $28.5 \mathrm{~kg} / \mathrm{m}^{2}$, with very severe airway obstruction and fatigue. Third, lower limb strength was greater in patients who did not fall. Fourth, the worse the balance test scores the greater the number of falls per year is.

Accidental falls in healthy individuals and patients with COPD are frequent, however, its causes must be better studied. These falls increase hip fractures risk and mortality representing greater economic spending for global health systems; old age is a risk factor for falls in the COPD population and is also associated with dyspnoea [17]. In this study, the mean age of subjects who had falls is greater than the age of those who did not fall, with a mean difference of 4.4 years between groups. Some studies have shown that the annual incidence of falls in patients with COPD is considerably higher when compared to healthy age matched adults [18,19]. Data from the present study are similar, 59 patients reported falls at least once in the last year, corresponding to $61.5 \%$ of all assessed patients (37 did not report any fall).

Patients with COPD have a balance deficit, probably due to multisystem diseases and old age; a risk factor for falls [20]. In a study comparing body balance impairment in patients with COPD and healthy peers matched for age and sex, loss of body balance was found among patients with COPD; body balance was more affected at more advanced age and airway obstruction in patients with COPD than in control subjects [9]. As age develops, postural control skills are altered, which lead to deficits in balance adjustments. These changes result from a decrease in the speed of neural information conduction, as well as in the muscle responses processing, most of those are slow and inadequate, leading to balance instability and increased falls predisposition.

In addition to age, we showed that overweight and mild-moderately obese COPD patients presented higher risk of falls as compared to their leaner counterparts. Some literature tried to explain its possible mechanisms for congestive heart failure, coronary heart disease and chronic obstructive pulmonary disease patients, however, most failed to do so mainly because evidence shows a protective effect, better prognosis and reduced mortality in these disease phenotypes; the so called "obese paradox" [21]. One study cited a possible explanation for this relating underlying disease such as diabetes, osteoarthritis, hypertension and anxiety disorders that would impair balance [22]. It is also seen that overweight may impact on lung volumes; the reduced $\mathrm{FEV}_{1}$ and FVC seen in our fallers COPD patients may be linked to a restrictive defect due to the modified chest wall mechanical properties related to increased fat mass-obese COPD patients may present [23].

The body balance was also analyzed in the present study, which was found to be impaired in the population that had fell

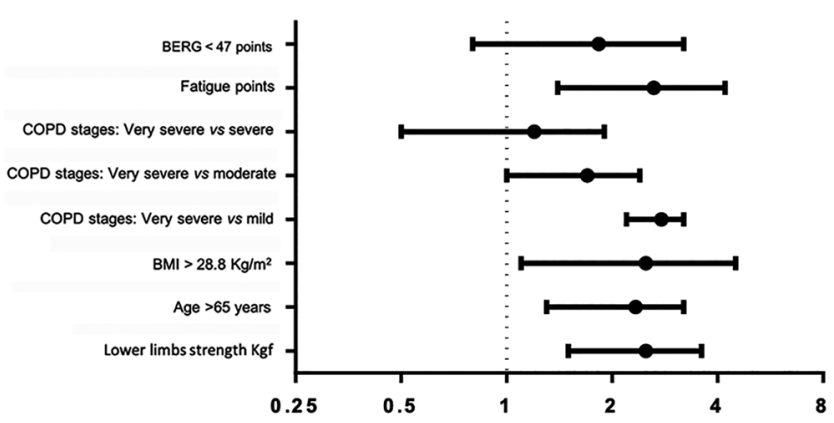

Figure 3. Forest plot for falls risk in patients with COPD. Berg, Berg scale; COPD stages, chronic obstructive pulmonary disease stages; BMI, body mass index. when compared to patients who did not fall. Other authors have shown that patients with COPD present postural control impairment when compared to age-matched healthy controls. Associated factors contributing to impaired postural control were muscle weakness, physical inactivity, elderly, need for supplemental oxygen and limited mobility [24].

A systematic review showed strong correlations between lower limb muscle weakness and the incidence of falls, assuming that muscle strength is an essential factor for postural control maintenance [24]. Another study showed reduced muscle strength and endurance in patients with COPD when compared with healthy controls. Their main finding is related to the lower limb strength mechanism is actively involved in the prevention of falls; unfortunately, that is impaired in COPD patients [25].

A decrease in muscle strength ultimately affects work capacity, motor activity and adaptability to the environment, contributing to instability and falls in elderly individuals. Several studies indicate a correlation between muscle weakness and falls in the elderly. Muscle weakness is the second leading cause of falls, along with balance and gait disturbances. According to this, attention should be drawn to the studied population, since a significant number of elderly people do not perform regular physical exercises and report muscle weakness in the lower limbs [24,25].

Although this study did not assess the frequency of systemic steroids use, it is known that patients with COPD take this medication for at least 14 days per year during post exacerbations periods [26,27]. Some authors relate these drugs use is ought to decrease muscular strength and balance, increasing the risk of accidental falls in patients with COPD. We can observe that lower limb muscle strength was reduced in patients who had fell; this being a precipitating factor for balance loss and consequent accidental falls.

Another study found that subjects with moderate to severe COPD $\left(\mathrm{FEV}_{1} 17 \%\right)$ had abnormal thigh muscles (reduced volume and strength and increased fat infiltration) when compared to a healthy control group [28,29]. These factors are associated to increased function and mobility loss in the elderly [19]. In the present study, we found that the group who fell presented reduced lower limb muscle strength and more severe disease according to GOLD classification than the group who did not fall.

Not only airway obstruction is related to falls in COPD due to reduced muscle strength but also due to the limited ventilation and hypoxemia COPD patients experiences [1,30]. In fact, the narrower airway is, more impaired postural control gets. Park et al. [31], showed that severe COPD patients had impaired postural balance compared to control subjects; also, they showed presence of oxygen therapy, fat mass, reduced neurocognitive function and the presence of diabetes explained most of the variation in postural balance in severe COPD patients. Additionally, Ozalevli et al. [30] reported that lower limbs fatigue also play an important role in COPD's postural balance. They showed an association between increased selfreported fatigue and balance impairment after manual quadriceps femoris muscle strength test and the six-minute walking test in COPD patients.

Therefore, our results showed it is not only one factor that determine fall in patients with COPD, quite contrary, it is a pool of factors that do; combined factors such as reduced lower limbs strength, older age, overweight, severe airway obstruction and lower limbs fatigue are associated with balance impairment in patients with COPD.

Our study has three limitations. First, its cross-sectional design does not allow us to evaluate the cause-effect relationship of tested variables. Longitudinal data are needed to further understand the 
causal and temporal relations between disease-related factors and balance and history of falls in COPD. Second, we used self-reported assessment methods to assess the frequency of falls. This method may lead to recall bias. Third, we did not assess the effect of medications, neuropathy, psychological factors (such as depression and anxiety), the prevalence of exacerbations, physical activity level, and comorbidities, which may all contribute to the increased fall risk and balance loss in COPD patients.

The clinical implication of this study is that specific balance and lower limb muscle strength training should be useful for patients with COPD. It is possible that specific training may reduce the number of falls in these patients.

\section{Conclusions}

Impaired body balance, reduced lower limb strength, old age, overweight, severe airway obstruction and lower limbs fatigue are related risk factors for balance impairment in COPD patients.

\section{References}

1. Vogelmeier CF, Criner GJ, Martinez FJ, Anzueto, et al. Global strategy for the diagnosis, management, and prevention of chronic obstructive lung disease 2017 report. GOLD executive summary. Am J Respir Crit Care Med 2017;195:557-82.

2. Lopez AD, K. Shibuya, C. Rao, et al. Chronic obstructive pulmonary disease: current burden and future projections. Eur Respir J 2006;27:397-412.

3. Agusti AGN, A. Noguera, J. Sauleda, et al. Busquets systemic effects of chronic obstructive pulmonary disease. Eur Respir J 2003;21:347-60.

4. MacIntyre NR. Mechanisms of functional loss in patients with chronic lung disease. Respir Care 2008;53:1177-84.

5. Ozalevli S, Ilgin D, Narin S. et al. Association between disease-related factors and balance and falls among the elderly with COPD: a cross-sectional study. Aging Clin Exp Res 2011;23:372-7.

6. Beauchamp MK, Hill K, Goldstein RS, et al. Impairments in balance discriminate fallers from non-fallers in COPD. Respir Med 2009;103:1885-91.

7. Dourado VZ, Tanni SE, Vale AS, et al. Systemic manifestations in chronic obstructive pulmonary disease. J Bras Pneumol 2006;32:161-71.

8. Nascimento MD, Benassi R, Caboclo FD, et al. [Valores de referência de força de preensão manual em ambos os gêneros e diferentes grupos etários. Um estudo de revisão].[in Portoguese]. EFDeportes.com [Internet]. 2010. Available from: https://www.efdeportes.com/efd151/forca-de-preensaomanual-em-ambos-os-generos.htm

9. Porto EF, Pradella CO, Rocco CM, et al. Comparative postural control in COPD patients and healthy individuals during dynamic and static activities. J Cardiopulm Rehabil Prev 2017;37:139-45.

10. Podsiadlo D, Richardson S. The timed 'Up \& Go': a test of basic functional mobility for frail elderly persons. J Am Geriatr Soc 1991;39:142-8.

11. Duncan PW, Weiner DK, Chandler J, Studenski S. Functional reach: a new clinical measure of balance. J Gerontol 1990;45:192-7.
12. Wall JC, Bell C, Campbell S. et al. The Timed Get-up-and-Go test revisited: measurement of the component tasks. J Rehabil Res Dev 2000;37(:109-13.

13. Tinetti ME. Performance-oriented assessment of mobility problems in elderly patients. J Am Geriatr Soc 1986;34:119-26.

14. Kegelmeyer DA, Kloos AD, Thomas KM, et al. Reliability and validity of the Tinetti Mobility Test for individuals with Parkinson disease. Phys Ther 2007;87:1369-78.

15. Morriss R, Wearden A, Mullis R. et al Exploring the validity of the Chalder Fatigue scale in chronic fatigue syndrome. J Psychosom Res 1998;45:411-7.

16. Jones PW, Harding G, Berry P, et al. Development and first validation of the COPD Assessment Test. Eur Respir J 2009;34:648-54.

17. Crişan AF, Oancea C, Timar B, et al. Balance impairment in patients with COPD. PloS One 2015;10:e0120573.

18. Oliveira CC, Lee AL, McGinley J, et al. Falls by individuals with chronic obstructive pulmonary disease: A preliminary 12-month prospective cohort study. Respirology 2015;20:1096-101.

19. Roig M, Eng JJ, MacIntyre D L, et al. Falls in people with chronic obstructive pulmonary disease: an observational cohort study. Respir Med 2011:105:461-9.

20. Porto EF, Castro AAM, Schmidt VGS, et al. Postural control in chronic obstructive pulmonary disease: a systematic review. Int J Chron Obstruct Pulmon Dis 2015;10:1233.

21. Chittal P, Babu AS, Lavie CJ. Obesity paradox: does fat alter outcomes in chronic obstructive pulmonary disease? COPD 2015;12:14-8.

22. Verberne LDM, Leemrijse CJ, Swinkels ICS, et al. Overweight in patients with chronic obstructive pulmonary disease needs more attention: a cross-sectional study in general practice. NPJ Prim Care Respir Med 2017;22;27:63.

23. Spelta F, Fratta Pasini AM, Cazzoletti L, Ferrari M. Body weight and mortality in COPD: focus on the obesity paradox. Eat Weight Disord 2018;23:15-22.

24. Beauchamp MK, Sibley KM, LakhaniB, et al. Impairments in systems underlying control of balance in COPD. Chest 2012;141:1496-503.

25. Moreland JD, Richardson JA, Goldsmith $\mathrm{CH}$, et al. Muscle weakness and falls in older adults: a systematic review and meta-analysis. J Am Geriatr Soc 2004;52:1121-9.

26. Clark CJ. Skeletal muscle strength and endurance in patients with mild COPD and the effects of weight training. Eur Respir J 2000;15:92-7.

27. Aaron SD, Vandemheen KL, Hebert $\mathrm{P}$, Dales R, et al. Outpatient oral prednisone after emergency treatment of chronic obstructive pulmonary disease. N Engl J Med 2003;348:2618-25.

28. Loke YK, Cavallazzi R, Singh S. Risk of fractures with inhaled corticosteroids in COPD: systematic review and meta-analysis of randomised controlled trials and observational studies. Thorax 2001;66:699-708.

29. Mathur S, Takai KP, MacIntyre DL, et al. Estimation of thigh muscle mass with magnetic resonance imaging in older adults and people with chronic obstructive pulmonary disease. Phys Ther 2008;88:219-30.

30. Ozalevli S, Ilgin D, Narin S, Akkoclu A. Association between disease-related factors and balance and falls among the elderly with COPD: a cross-sectional study. Aging Clin Exp Res 2011;23:372-7.

31. Park JK, Deutz NEP, Cruthirds CL, et al. Risk factors for postural and functional balance impairment in patients with chronic obstructive pulmonary disease. J Clin Med 2020;9:609. 